\title{
Chemometric comparison of almond oxidation rates using kinetic parameters obtained by infrared spectroscopy
}

Running title: Almond cultivar comparison based on oil oxidation rates using infrared spectroscopy

Iván P. Román Falcó, Soledad Prats Moya*, Salvador E. Maestre Pérez, M. Luisa Martín Carratalá, Nuria Grané Teruel

Analytical Chemistry, Nutrition and Food Science Department, University of Alicante, Alicante, Spain

*Correspondence to M. Soledad. Prats Moya, Analytical Chemistry, Nutrition and Food Science Department, University of Alicante, P.O. Box 99, 03050 Alicante, Spain. E-mail: maria.prats@ua.es

This article has been accepted for publication and undergone full peer review but has not been through the copyediting, typesetting, pagination and proofreading process which may lead to differences between this version and the Version of Record. Please cite this article as doi: $10.1002 /$ jsfa.10513 


\begin{abstract}
BACKGROUND: The study of almond fat stability is essential from a quality control perspective meanly because, in most of the cases, almonds are sold skinned and thermally treated. In this work an alternative method to Rancimat test based on Attenuated Total Reflectance-Fourier Transform Infrared Spectrometry (ATR-FTIR) was adapted for checking the induced degradation at $75{ }^{\circ} \mathrm{C}$ of seven almond oil cultivars, three of top California producing varieties, and, four traditional cultivars harvested in Spain.
\end{abstract}

RESULTS: The thermal oil degradation evolution was followed by measuring the changes in the absorbance of the selected FTIR spectra bands (3470, 3006, 1730, 1630, 988 and $970 \mathrm{~cm}^{-1}$ ). A first-order kinetic behaviour was observed, after an induction time in all bands.

CONCLUSIONS: Kinetic coefficients and induction times were easily obtained as the absorbance values (from difference spectra) fitted to pseudo-first-order kinetics after the induction time. Principal Component analysis was applied to the kinetic parameters to visualised which variables could be useful to classify the almond cultivars based on their resistance to thermal oxidation processes. It was found that selecting only the induction times corresponding to the bands 3470, 3006, 1630 and $970 \mathrm{~cm}^{-1}$ a separate classification of the Californian cultivars from the Spanish ones was possible. Finally, a linear discriminant analysis was assayed using only the four induction times previously selected. Validated classification and correct in $100 \%$ of the cases was obtained for all the samples based on their Spanish or Californian origin.

KEYWORDS: almond oil, oxidation, cultivar; FTIR, PCA, LDA 


\section{INTRODUCTION}

Almond is the most widely produced tree nut in the world. ${ }^{1}$ USA, Australia, and Spain led the world production in 2018/19 accounted for roughly $90 \%$ of the overall almond production. Furthermore, nutritional properties of almonds are related to the chemical composition of kernels. In this sense, antioxidants and fatty acids are the compound families on which scientific attention has been mainly focused. ${ }^{2}$ In this context, the influence of the cultivar, i.e., genotype, harvesting conditions, and maturity stage of the fruit, on the chemical composition of the kernel has been evaluated, with particular emphasis on the fatty acid profile and tocopherol content. ${ }^{3-6}$

The fatty acid profile of almonds is mostly unsaturated with oleic acid and linoleic acid accounting for $600-700 \mathrm{~g} \mathrm{~kg}^{-1}$ and $150-250 \mathrm{~g} \mathrm{~kg}^{-1}$, respectively. ${ }^{2,7}$ The unsaturated nature of this oil makes almonds very interesting from a nutritional point of view but also quite susceptible to degradation. Fat degradation is a very complicated chemical process that strongly depends on the fat composition and external conditions including temperature, time, oxygen concentration, light, radicals, peroxides, and metals, which catalyse the degradation reactions. ${ }^{8,9}$ Additionally, other minor components present in the kernel may influence on the oxidation process as well, for example, fat-soluble antioxidants such as tocopherols, carotenoids or polyphenols.. ${ }^{10,11}$

The study of almond fat stability is critical because, due to its seasonal character, almonds are usually stored during several months before their consumption. Moreover, a thermal treatment, such as roasting, frying or baking is usually applied to almonds and to products containing almonds, boosting oxidation processes. The characterisation of the oxidation 
process of almonds during storage has been extensively treated in literature. ${ }^{12,13}$ Some studies have addressed the oxidation of kernels after being processed and packed. ${ }^{14-16}$ Others have centered in the evaluation of the best storage conditions and to study the shelf life of the almonds. ${ }^{17}$ Finally, the oxidation of the isolated oil fraction has also been evaluated. ${ }^{18}$ As for other food fats, oxidation induces changes in almond chemical composition. Briefly, hydroperoxides are formed from unsaturated fatty acids, and then the hydroperoxides continue the decomposition process producing different volatile compounds. ${ }^{19-22}$ Also, the appearance of glycation end-products due to the Maillard reaction is enhanced. ${ }^{23}$ Moreover, cis-trans isomerisation of unsaturated fatty acids and other compounds is accelerated in thermally treated oils. ${ }^{18}$ All these changes in composition have already been monitored using different instrumental analytical techniques such as gas chromatography (GC) with flame ionization detector (FID) or mass spectrometry (MS), and even liquid chromatography (LC) with different detectors. Nevertheless, in food quality control, the current trend is to use those techniques that provide fast results with the lowest running costs and the lowest environmental impact. In this way, FTIR spectrometry appears to be an ideal technique that fulfils those characteristics.

FTIR has successfully been previously employed to study the fat composition ${ }^{24-26}$ and oxidation status of fats and vegetable oils. ${ }^{27-32}$ Under thermal stress, absorbance changes of specific regions of oils spectra are well documented and assigned to oil compositional changes. ${ }^{33-34}$ The data obtained can be interpreted with chemometric techniques to extract useful conclusions. 
This study aims to develop a simple and alternative procedure for the study of almond cultivars resistant to oxidation based in kinetic parameters (i.e. induction times and kinetics coefficients) using FTIR discrete measurements after an induced thermal degradation process. To achieve this purpose, a selection of seven cultivars was made, three from the leading world producer, i.e. the USA (US), and four typical almond cultivars from Spain (SP). The study was divided into several parts, firstly, the selection of the best spectral FTIR bands for the study and the validation of the kinetic mechanism involved in the process of almond oil oxidation. Secondly, the determination of the induction times and the kinetic coefficients, for all the samples studied, using an experimental layout with the least number of days. Finally, the application of chemometric techniques to check if it is possible to find differences among almond oil cultivars based on the kinetic degradation variables.

\section{MATERIALS AND METHODS}

\section{Samples}

Seventy-six almond samples were collected from seven representative cultivars. The cultivars selected were: three of the top five of California producing varieties, i.e. Carmel (CA), Non Pareil (NP) and Butte (BU) and, four traditional cultivars harvested in Spain, Desmayo-Largueta (DL), Garrigues (GA), Guara (GU)) and Marcona (MR). In the study, ten samples for each cultivar were collected from different locations except for MR, for which sixteen different samples were included. Most samples of Spanish cultivars were obtained from agronomical standard almond trees cultivated in experimental fields of the 
Research Center CEBAS (Centro de Edafología y Biología Aplicada del Segura, MurciaSpain) and SIA (Unidad de Fruticultura del Servicio de Investigaciones Agrarias, Zaragoza-Spain). The remaining samples of the Spanish cultivars were obtained from a Spanish trader. The American samples were purchased from two different almond importers from California.

\section{Sample preparation}

Spanish almonds were purchased with shell; meanwhile, the Californian ones were acquired unshelled. After purchasing all samples were stored, unshelled, in vacuum plastic bags in the fridge at $7^{\circ} \mathrm{C}$ until processed. All samples were blanched introducing then in boiling water for one minute. The tegument came off quickly after the process and the almonds were left to dry on a desiccant paper for $1 \mathrm{~h}$ at room temperature. Afterwards, the unskinned almonds were ground in a domestic electric grinder (Moulinex, Barcelona, Spain) and the fraction which passed through a 1,5 mm light sieve was retained. Samples were then dried at $60^{\circ} \mathrm{C}$, stored in a desiccator, and finally submitted to fat extraction. A commercial fat Soxhlet extractor (Selecta, Barcelona, Spain) was used for the extraction of almond oils. Approximatively, 4 grams of ground and sieved almond was extracted with $40 \mathrm{~mL}$ of analytical grade petroleum ether (Panreac, Barcelona, Spain) during 90 minutes following the procedure previously published. ${ }^{18}$ Obtained oils were kept in the dark bottles inside the refrigerator at $5{ }^{\circ} \mathrm{C}$ until the moment they were used.

\section{Sample degradation}


Three grams of each almond oil sample were placed in glass vials of $2.5 \mathrm{~cm}$ diameter and $3 \mathrm{~cm}$ high for each experimental day. The almond oils degradation was carried out leaving the oils at $75^{\circ} \mathrm{C}$ in an oven. A first experiment using only samples of the cultivar MR was performed to choose the best spectral bands for the study and to verify the kinetic oxidation process. For that purpose, an aliquot of the treated oil was taken every two days for the measurement of the FTIR spectrum until the sample became so viscous that taking the oil from the vial was very difficult (i.e. 36 days for the oil that lasted longer). These experiments provided approximate references about the relative thermal stability of the oil to set the experimental timeframe for the following experiments, that is, the time needed to approach the induction time.

In the second part of the experiment, once the timeframe was determined, the same thermal process was applied for all the samples included in the study. In this case, the spectra were recorded every five days based on the information obtained in the first part. Hence, a total of 380 vials were prepared, one vial per sample to be used every five days during a month. Samples of all cultivars were included in this part of the study.

\section{Spectra acquisition}

TheThe FTIR Spectrometer, Vector 22 (Bruker, Ettlingen, Germany) was equipped with a ZnSe attenuated total reflection device (Gateway ATR kit is a six-reflection horizontal ATR sampling accessory with a Through Top Plate from Specac). FTIR was interfaced with a computer operating under OPUS NT software (version 3.1). Spectra from 1 gram of oil sample were recorded from 4000 to $650 \mathrm{~cm}^{-1}$ co-adding 128 scans at a $4 \mathrm{~cm}^{-1}$ 
resolution and a gain of 2.0. The ATR sampling accessory was cleaned with a soft paper tissue moistened with acetone every time a sample was changed. A background spectrum was recorded after every sample acquisition to check the performance of the cleaning procedure.

\section{Data acquisition and processing}

Rutherford baseline correction was carried out from 64 baseline points excluding carbon dioxide region (OPUS version 3.1). The absorbance data referred to band height was measured with the software peak peaking command, by tracing a baseline between two adjacent minima to reduce errors due to overlapping bands. The absorbance of the selected bands was measured from the difference spectra, obtained by subtracting the spectrum of fresh oil from each sample to the spectrum of the same oil at each thermal treatment day using the OPUS software (Version 3.1).

\section{Kinetic Parameter calculation}

At moderate temperatures, due to the high oxygen concentration dissolved in the oil, the lipid oxidation could be assumed to be independent of the oxygen pressure, and the oxidation rate will follow pseudo-first-order kinetics. ${ }^{31,35,36}$ Therefore, the value of the pseudo-first-order coefficient $(\mathrm{k})$ and the induction time $\left(\mathrm{t}_{\mathrm{ind}}\right)$ for each reaction can be obtained from the slope of the adjusted line and the origin coordinate, respectively after plotting the $\ln [A]$ (absorbance of each product band) vs $t$ (for $\mathrm{t}>$ tind) (see the equation 
in Table 1). In a previous publication, a more detailed discussion on this topic is shown. 31

\section{Statistical Analysis}

The data reported are averages of triplicate spectra. Experimental data were processed with the help of the software package IBM SPSS statistics (version 19, SPSS Inc., Chicago, IL, USA). One-way analysis of variance (ANOVA) was applied to determine the capability of kinetic parameters to differentiate among sets of almond oil samples. Principal Component Analysis (PCA) was applied to obtain an unsupervised classification of the samples using the "prcomp" function of the R software ${ }^{37}$. After the selection of the best variables for the classification, a supervised pattern recognition method such as linear discriminant analysis (LDA) was used, to this end the "lda" function from the [MASS package] of R was employed. Besides, cross-validation was applied to estimate how accurate the predictive classification was. In this application "leave one out" was the cross-validation approach selected using the [Caret package] of R. ${ }^{37}$

\section{RESULTS AND DISCUSSION}

\section{Optimization of the methodology}

Initial experiments were carried out using MR samples to establish the best time frame for the kinetic study, MR was selected as is one of the most extended and high organoleptic quality of the Spanish cultivars. The degradation process of this oil was monitored using the FTIR spectra obtained every two days for 36 days. 
The difference spectra of the oil treated at different oxidation days are shown in Fig. 1. In the figure, the wavenumbers identify the regions in which the more apparent modifications appear along with the study. Assignation of most of these spectrum features to chemical modification of oil components was carried out before in literature. ${ }^{18,26,32}$ Hence, in this work, some bands have been found especially suitable for monitoring the oxidation process (i.e., 3470, 1730, and $1630 \mathrm{~cm}^{-1}$ ), and others for tracking the isomerisation process (i.e. 3006, 988, and $970 \mathrm{~cm}^{-1}$ ). In contrast, other spectral regions, which show changes in the absorbance values (Fig. 1 left), were not included in this work because their assignment to a chemical process was not clear or due to the high uncertainty of the measurement. Moreover, two strong bands assigned to $\mathrm{CH}$ bond stretching of methyl and methylene groups at around $2922 \mathrm{~cm}^{-1}$ and $2853 \mathrm{~cm}^{-1}$, changed on heating. These strong bands, after the induction time, shifted with time towards higher wavenumbers (2924 $\mathrm{cm}^{-1}$ and $2854 \mathrm{~cm}^{-1}$, respectively), and they become broader in the evolution of absorbance spectra.

Thus, the evolution with time of the selected FTIR bands was employed to characterise the kinetics of reactions happening during thermal treatment of the almond oils. The changes on the band signals can be related to modifications in the chemical composition through the kinetic equations for the disappearance of one or more reactants (A) and the appearance of one or more reaction products $(\mathrm{P})$. Table 1 summarises the equations for zero and first-order kinetics. Only if the signal of the reactants or products is proportional to the concentrations (being $k_{\mathrm{A}}$ and $k_{\mathrm{P}}$ the proportionality coefficients), these equations can be rewritten in terms of signals instead of concentrations of compounds. 
Overall, all used bands showed a similar pattern after plotting [A] vs time (t). Initially, in the treatment, there was a period of time where no significant changes in the band absorbance were found i.e., the induction time ( $\left.t_{\text {ind }}\right)$. Afterwards, a stage of rather sharp changes was observed. These variations in the absorbance were fitted to pseudo-firstorder kinetics. As shown in Table 1, first-order kinetics reactions are the unique ones that are independent of the relationship between concentration and signal, so there is no need for calibration to determine the kinetic parameters, such as the kinetic coefficient (independent of the concentration).

Consequently, the kinetic parameters (i.e., $\mathrm{k}$ and tind) could be obtained by plotting $\ln [\mathrm{A}]$ vs $t$ (time). For $\mathrm{t}>$ tind a straight line is obtained if the reaction fits a pseudo-first-order kinetic. From the slope of this straight line, the $k$ values can be derived. Moreover, from its intercept and the signal of the characteristic band, the induction time can also be obtained. Results of these calculations are shown in Table 2 for cultivar MR.

The pseudo-first-order kinetics was confirmed for both the cis-double bond degradation (3006 $\left.\mathrm{cm}^{-1}\right)$ and the trans-double bonds formation $\left(970 \mathrm{~cm}^{-1}\right)$ as was previously observed in olive oils, ${ }^{31}$ so the kinetics for cis-trans isomerisation was also confirmed. Moreover, the same pseudo-first-order was observed for the bands at 3470, 1730 and $1630 \mathrm{~cm}^{-1}$ (Table 2). These five bands were selected for the cultivar comparison study. Regarding the $988 \mathrm{~cm}^{-1}$ signals, this band disappeared overlapped by the trans double bond band (at $970 \mathrm{~cm}^{-1}$ ) along the degradation process (Fig. 1, right). This band was assigned to conjugated linoleic acid (CLA). Low activation energy can explain the high speed of isomerization of linoleic acid..$^{38}$ 
It is well-known that the radical mechanism of lipid oxidation has two propagation steps. In the first step, a radical of the fatty acid is formed by radical hydrogen abstraction. Therefore, isomerisation could take place- This phenomenon could explain the faster isomerization of linoleic acid as in lipid oxidation, ${ }^{39}$ the allylic reaction intermediate is more stable and therefore, the reactivity is higher. Additionally, the trans-isomerisation of double bonds of unsaturated fatty acids was influenced by antioxidants in edible oils. 40

Hence the confirmation of the kinetics of the reactions quoted previously implies that the corresponding $\mathrm{k}$ and tind values could be obtained by using a set of 3-5 points (minimum needed to perform a linear regression analysis) after the induction period has been overcome. This result showed that spectra acquisition every five days would be enough to obtain the kinetic coefficient. This conclusion was used to establish the timeframe setup of the following experiments.

\section{Comparison of kinetic thermal degradation parameters for seven almond cultivars}

Once the oxidation kinetic was verified, and to simplify the experiments, a procedure with considerably reduced sampling days was designed. The ATR-FTIR spectra were measured on specific days along the heat treatment process. The obtained kinetic parameters for each band of the almond oils are summarised in Fig. 2. Data include the mean as well as maximum and minimum values obtained for each set of oils from each almond cultivar. 
As shown in Fig. 2a, the kinetic coefficient values for the different bands vary from 0.010 day $^{-1}$ (band at $1630 \mathrm{~cm}^{-1}$ for NP cultivar with mean value 0.0149 day $^{-1}$ ) to 0.41 day $^{-1}$ (band at $988 \mathrm{~cm}^{-1}$ for BU cultivar with mean value 0.322 day $^{-1}$ ). It should be noted that the highest mean values for the kinetic coefficients are those of the band at $988 \mathrm{~cm}^{-1}$ associated with the conjugated trans-trans double bond. The mean values of the coefficients for this band are markedly higher than the average coefficient values from other bands. Almond oils from the BU cultivar showed the highest mean value of kinetic coefficients for all bands reported, except for the band at $1730 \mathrm{~cm}^{-1}$ for which the DL cultivar exceeded average kinetic coefficient value. Higher kinetic coefficient values imply faster reaction rates after the induction time. Under the thermal treatment employed in this work, the degradation rates for BU oils were higher than for the rest of cultivars. The higher proportion in linoleic acid described in bibliography for Californian cultivars has also an influence on it. ${ }^{41,42}$ Meanwhile, the induction times mean values (Fig. 2b) range from 3.1 days (band at $1630 \mathrm{~cm}^{-1}$ for NP cultivar with mean value 3.9 days) to 17.4 days (band $3006 \mathrm{~cm}^{-1}$ for DL cultivar with mean value 16.4 days). Shorter mean induction times were observed for BU, CA, and NP cultivars compared to the other cultivars but for the $1730 \mathrm{~cm}^{-1}$ band. This overall trend shows that the selected Spanish almonds have a higher resistance to degradation during the first steps of degradation. The shortest average values of the induction time were observed for most of the BU cultivar bands. As a result of that, DL can be considered the cultivar with the highest resistance to thermally induced deterioration during the initial period. This result reflects differences in the kernel composition such as the higher content of linoleic acid and lower in oleic acid ${ }^{19,41,43}$ 
or/and lower antioxidant content ${ }^{44}$ in the less resistant to oxidation cultivars. The relationship between oleic acid and linoleic acid is higher than three for cultivars MR, GA, GU and DL and lower than 3 for NP, CA and BU. ${ }^{41,45}$ The higher proportion in linoleic acid found in Californian cultivars explains partly the differences in the induction time found even though that the antioxidant power has also a significant influence on it.

\section{Chemometric approach for the classification of almond cultivars}

An Analysis of Variance (ANOVA) was applied to explore the capability of kinetic parameters to differentiate almond oils based on their resistant to degradation. The statistical F-value and its significance for each kinetic parameter were calculated for the studied almond cultivars oils. The results showed that all kinetic parameters establish statistically significant differences with $\mathrm{p}<0.001$ among cultivars. A Tukey test for multiple pairwise comparisons (confidence level $95 \%$ ) was applied to determine the mean values which could be used to differentiate the oxidation behaviour of different cultivar oils. The results of the Tukey test are shown in Table 3. As can be seen, differentiation among all cultivars was not possible using a single measured kinetic parameter. The capability of mean values of these parameters to differentiate monovarietal oils was calculated based on the relative percentage of statistically significant differences found. This percentage was obtained as the ratio of the established differences to all the possible differences (i.e., 21 differences).

Firstly, the differentiation established by the kinetic coefficients were, in decreasing order: $\mathrm{k}_{3006}(90 \%)>\mathrm{k}_{3470}(86 \%)>\mathrm{k}_{1630}=\mathrm{k}_{988}(67 \%)>\mathrm{k}_{1730}(62 \%)>\mathrm{k}_{970}(29 \%)$. These 
results showed that the band at $3006 \mathrm{~cm}^{-1}$ provided the highest capability to differentiate cultivars, while the kinetic coefficient for the band at $970 \mathrm{~cm}^{-1}$ showed less statistically significant differences.

On the other hand, the differentiation percentages established using only the induction times were, also in decreasing order: tind band at $3006 \mathrm{~cm}^{-1}(91 \%)>t_{\text {ind }}$ band at $3470 \mathrm{~cm}^{-}$ ${ }^{1}=\mathrm{t}_{\text {ind }}$ band at $988 \mathrm{~cm}^{-1}=\mathrm{t}_{\text {ind }}$ band at $970 \mathrm{~cm}^{-1}(85 \%)=\mathrm{t}_{\text {ind }}$ band at $1630 \mathrm{~cm}^{-1}(86 \%)>$ $t_{\text {ind }}$ band at $1730 \mathrm{~cm}^{-1}$ (71\%). The induction time for the band at $3006 \mathrm{~cm}^{-1}$ provided the largest number of differences between the oils; meanwhile, the induction time for the band at $1730 \mathrm{~cm}^{-1}$ showed fewer statistically significant differences.

It is noteworthy that the set of induction time values showed higher differentiation capabilities than the kinetic coefficients set because a higher number of differences between oils were observed. Thus, the induction time values of the bands 3470, 3006, 1630, 988 and $970 \mathrm{~cm}^{-1}$ allowed the differentiation among the almond cultivars harvested in both countries. Being 988 and $970 \mathrm{~cm}^{-1}$ bands highly correlated, so using only one will be enough.

This study showed how kinetic parameters obtained by FTIR could be useful for the characterisation of almond cultivars, although none of them, taken individually or grouped by the band, can be used to differentiate among all the cultivars studied.

A PCA was applied to the 12 kinetic variables trying to found out a classification of the almond cultivars but reducing the dimensionality of the original variables.

Firstly, the correlation matrix and the associated significance level were calculated to evaluate the adequacy of the data set for PCA application, and the correlation coefficients 
are shown as a correlogram (Fig. 3). In the correlogram, the positive correlations are shown in blue and the negative ones in red. High correlations were found over more than $50 \%$ of the possible combinations with a significance $\mathrm{p}<0.05$. The data adequacy was verified by the application of Kaiser-Meyer-Olkin (KMO) and Bartlett's test of sphericity, which provided value for Chi-Square of $993.342(\mathrm{p}<0.001)$.

After performing the PCA, and according to Guttman-Kaiser criterion, the total variance of the data retained by the two first principal components was $70 \%$. The communality values for the original variables ranged between $0.934\left(\mathrm{t}_{\text {ind3006 }}\right)$ and $0.735\left(\mathrm{k}_{970}\right)$. These high communality values indicated that all variables were sufficiently contained in the model. The proposed model fitted well because more than $50 \%$ of the calculated residual correlations showed absolute values lower than 0.025 .

Fig. 4 shows the loadings obtained for each of the original variables (a) and the loading obtained for each sample (b) in the reduced space formed by the two retained principal components. From these plots, different conclusions could be drawn. Firstly, the PC1 showed high loading values for all the induction times; all these loadings were positive. The loadings of induction times found in PC2 were lower compared to PC1, but it is noteworthy that in all cases were positive and with an essential contribution to the total variance.

Concerning the kinetic coefficients, all loadings showed negative values on PC1 with absolute values lower than the loading values of the induction times, except for the band at $988 \mathrm{~cm}^{-1}$. This result could be attributed to the higher value of this coefficient when compared to the coefficients of the others (see Fig. 2a). Only the loadings of the kinetic 
coefficients corresponding to the bands $\mathrm{k}_{3470}$, $\mathrm{k}_{988}$ and $\mathrm{k}_{1730}$ have a significant contribution to the total variance (Fig. 4a).

Fig. 4 b shows the scores values of the samples in the reduced space formed by the two first principal components retained. At first, the most remarkable result is that the four Spanish cultivars could be classified separately from the Californian ones because all Spanish samples show positive values on PC1 meanwhile, the three Californian cultivars showed negative values. Scores with negative values on PC1 are associated with shorter induction times; meanwhile, high positive values on PC1 denote long induction times. In general, the biplot shows that the behaviour of BU samples is markedly different from the rest of cultivars considered because their loadings were positive on PC1 and negative on PC2. Almond samples from NP and CA cultivars are displayed close to each other, with negative loading for both PCs. In general, the Spanish samples were differentiated from Californian cultivars even using only the PC1. On the contrary, the four Spanish cultivars appear entirely mixed. These results show that kinetic parameters can be useful variables to classified and select almonds that have different behaviour under thermal oxidation stress.

After the ANOVA and PCA analysis, it seemed that the induction time values of the bands at 3470, 3006, 1630 and $970 \mathrm{~cm}^{-1}$ could be used to establish a classification of the almond cultivars based on their origin. Consequently, a supervised pattern recognition method such as linear discriminant analysis (LDA) was used to verify if a separated classification of the SP and US almond oil cultivars was possible using the quoted variables. As only two sets of samples were fixed, only one discriminant function was obtained. This 
discriminant function allowed a great separation of the SP samples from the US ones, as it is shown in the stacked histogram of the values of the discriminant function on the training set for the samples from different groups (Fig. 5). It can be seen from the histogram that the SP cultivars appear completely separated from the values for the US. The classification was validated by randomly splitting the data into two sets of samples. One set was used to train the model, and it was constituted by $75 \%$ of the data, i.e. 56 samples. Meanwhile the rest of the samples (25\%), were used to test the model and predict the outcome of non-included observations in the model. Thus, the prediction error was calculated as the mean squared difference between the observed and the predicted outcome values. The model assayed showed $0 \%$ of prediction error since the confusion matrix obtained showed correct prediction classification for all the SP and US from the test set. ${ }^{46}$

\section{CONCLUSION}

Therefore, the relevance of the kinetic parameters for almond oil characterisation was demonstrated. As a conclusion using only four induction times, it is possible to deduce which are the most resistant cultivars to thermal stress oxidation, and this is related to the shelf life of the almonds. In this study, the classification conducted to obtain a validated classification of the SP cultivars separated to the US cultivars. The reduction in variables is essential because not only the experiments are greatly simplified but also the data treatment. 
One of the most important findings that are established in this work is that it is possible to determine the kinetic parameters with a simplified procedure with a few FTIR measurements of the fresh oil and oil samples during the degradation when spectral changes are observed that fit the line model. Therefore, this strategy reduces the handling and measuring time in the laboratory compared to other techniques.

\section{ACKNOWLEDGEMENTS}

The authors would like to thank CEBAS (Murcia), Spanish trader Frutos Secos MAÑAN (Pinoso-Alicante, Spain), SIA (Zaragoza), Cooperativa de Alcañiz (Teruel) for providing almond samples from Spanish cultivars; and in the case of American cultivar samples to the importers LLOPIS (San Vicente del Raspeig-Alicante, Spain) and COLEFRUSE (Jijona- Alicante, Spain).

\section{CONFLICT OF INTEREST}

The authors declare no conflicts of interest. 


\section{REFERENCES}

1 Global Statistical review 2014-2015. The Foundation of the International Nut and Dried Fruit Council;

2 Yada S, Lapsley K, and Huang G. A review of composition studies of cultivated almonds: Macronutrients and micronutrients. J Food Compos Anal Elsevier Inc.; 24:469-480 (2011).

3 Sánchez-Bel P, Egea I, Martínez-Madrid MC, Flores B, and Romojaro F. Influence of irrigation and organic/inorganic fertilization on chemical quality of almond (Prunus amygdalus cv. Guara). J Agric Food Chem 56:10056-10062 (2008).

4 Zhu Y, Taylor C, Sommer K, Wilkinson K, and Wirthensohn M. Influence of deficit irrigation strategies on fatty acid and tocopherol concentration of almond (Prunus dulcis). Food Chem 173:821-826 (2015).

5 Yada S, Huang G, and Lapsley K. Natural variability in the nutrient composition of california-grown almonds. J Food Compos Anal Elsevier Inc.; 30:80-85 (2013).

6 Rabadán A, Álvarez-Ortí M, and Pardo JE. A comparison of the effect of genotype and weather conditions on the nutritional composition of most important commercial nuts. Sci Hortic (Amsterdam) 244:218-224 (2019).

7 García-López C, Grané-Teruel N, Berenguer-Navarro V, García-García JE, and Martín-Carratalá ML. Major fatty acid composition of 19 almond cultivars of different origins. A chemometric approach. J Agric Food Chem 44:1751-1755 
(1996).

$8 \quad$ Frankel EN. Lipid oxidation. Prog Lipid Res 19:1-22 (1980).

9 Angelo AJ St., Vercellotti J, Jacks T, and Legendre M. Lipid oxidation in foods. Crit Rev Food Sci Nutr 36:175-224 (1996).

10 López Ortíz CMM, Prats Moya MSMS, and Berenguer Navarro V. A rapid chromatographic method for simultaneous determination of $\beta$-sitosterol and tocopherol homologues in vegetable oils. J Food Compos Anal 19:141-149 (2006).

11 Kodad O, Estopañán G, Juan T, and Mamouni A. Tocopherol concentration in almond oil: Genetic variation and environmental effects under warm conditions. J Agric Food Chem 59:6137-6141 (2011).

12 Zacheo G, Cappello AR, Perrone LM, and Gnoni G V. Analysis of factors influencing lipid oxidation of almond seeds during accelerated ageing. LWTFood Sci Technol 31:6-9 (1998).

13 Zacheo G, Capello MS, Gallo A, and Capello AR. Changes Associated with Post-Harvest Ageing in Almond Seeds. 33:415-423 (2000).

14 Severini C, Gomes T, Pilli T De, Romani S, and Massini R. Autoxidation of packed almonds as affected by Maillard reaction volatile compounds derived from roasting. J Agric Food Chem 48:4635-4640 (2000).

15 García-Pascual P, Mateos M, Carbonell V, and Salazar D. Influence of Storage Conditions on the Quality of Shelled and Roasted Almonds. Biosyst Eng 84:201209 (2003). 
16 Sanchez-Bel P, Egea I, Pretel MT, Flores FB, Romojaro F, and Martínez-Madrid MC. Roasting and packaging in nitrogen atmosphere protect almond var. Guara against lipid oxidation. Food Sci Technol Int 17:529-540 (2011).

17 Gama T, Wallace HM, Trueman SJ, and Hosseini-Bai S. Quality and shelf life of tree nuts: A review. Sci Hortic (Amsterdam) Elsevier; 242:116-126 (2018).

18 Beltran Sanahuja A, Prats Moya MS, Maestre Pérez SE, Grané Teruel N, and Martín Carratalá ML. Classification of four almond cultivars using oil degradation parameters based on FTIR and GC data. JAOCS, J Am Oil Chem Soc John Wiley \& Sons, Ltd; 86:51-58 (2009).

19 Beltrán Sanahuja A, Ramos Santonja M, Grané Teruel N, Martín Carratalá ML, and Garrigós Selva MC. Classification of almond cultivars using oil volatile compound determination by HS-SPME-GC-MS. JAOCS, J Am Oil Chem Soc John Wiley \& Sons, Ltd; 88:329-336 (2011).

20 Xiao L, Lee J, Zhang G, Ebeler SE, Wickramasinghe N, Seiber J, and Mitchell AE. HS-SPME GC/MS characterization of volatiles in raw and dry-roasted almonds (Prunus dulcis). Food Chem 151:31-39 (2014).

21 Beltrán A, Ramos M, Grané N, Martín ML, and Garrigós MC. Monitoring the oxidation of almond oils by HS-SPME-GC-MS and ATR-FTIR: Application of volatile compounds determination to cultivar authenticity. Food Chem 126:603609 (2011).

22 Valdés A, Beltrán A, Karabagias I, Badeka A, Kontominas MG, and Garrigós MC. Monitoring the oxidative stability and volatiles in blanched, roasted and 
fried almonds under normal and accelerated storage conditions by DSC, thermogravimetric analysis and ATR-FTIR. Eur J Lipid Sci Technol John Wiley \& Sons, Ltd; 117 (2015).

23 Zhang G, Huang G, Xiao L, and Mitchell AE. Determination of Advanced Glycation Endproducts by LC-MS/MS in Raw and Roasted Almonds (Prunus dulcis). J Agric Food Chem 59:12037-12046 (2011).

24 Vlachos N, Skopelitis Y, Psaroudaki M, Konstantinidou V, Chatzilazarou A, and Tegou E. Applications of Fourier transform-infrared spectroscopy to edible oils. Anal Chim Acta 573-574:459-465 (2006).

25 Dupuy N, Duponchel L, Huvenne JP, Sombret B, and Legrand P. Classification of edible fats and oils by principal component analysis of Fourier transform infrared spectra. Food Chem 57:245-251 (1996).

26 Guillén MD and Cabo N. Infrared spectroscopy in the study of edible oils and fats. J Sci Food Agric 75:1-11 (1997).

27 Mahesar SA, Bendini A, Cerretani L, Bonoli-Carbognin M, and Sherazi STH. Application of a spectroscopic method to estimate the olive oil oxidative status. Eur J Lipid Sci Technol 112:1356-1362 (2010).

28 Ruíz A, Cañada MJA, and Lendl B. A rapid method for peroxide value determination in edible oils based on flow analysis with Fourier transform infrared spectroscopic detection. Analyst 126:242-246 (2001).

29 Guillén MD and Goicoechea E. Detection of primary and secondary oxidation products by fourier transform infrared spectroscopy (FTIR) and 1H nuclear 
magnetic resonance (NMR) in sunflower oil during storage. J Agric Food Chem 55:10729-10736 (2007).

Guillén MD and Cabo N. Fourier transform infrared spectra data versus peroxide and anisidine values to determine oxidative stability of edible oils. Food Chem 77:503-510 (2002).

31 Román Falcó IPP, Grané Teruel N, Prats Moya S, and Martín Carratalá MLL. Kinetic study of olive oil degradation monitored by fourier transform infrared spectrometry. Application to oil characterization. J Agric Food Chem Departamento de Química Analítica, Nutrición y Bromatología, Facultad de Ciencias, Universidad de Alicante, Alicante 03080, Spain; 60:11800-11810 (2012).

Voort FR Van de, Ismail AA, Sedman J, and Emo G. Monitoring the oxidation of edible oils by Fourier transform infrared spectroscopy. J Am Oil Chem Soc 71:243-253 (1994).

33 Esonye C, Onukwuli OD, and Ofoefule AU. Characterization and oxidation modeling of oils from Prunus amygdalus, Dyacrodes edulis and Chrysophyllum albidium. Ind Crops Prod Elsevier; 128:298-307 (2019).

34 Guillén MD and Cabo N. Some of the most significant changes in the Fourier transform infrared spectra of edible oils under oxidative conditions. J Sci Food Agric 80:2028-2036 (2000).

35 Christy AA, Xu Z, and Harrington P de B. Thermal degradation and isomerisation kinetics of triolein studied by infrared spectrometry and GC-MS 
combined with chemometrics. Chem Phys Lipids 158:22-31 (2009).

36 Cordella CBY, Tekye T, Rutledge DN, and Leardi R. A multiway chemometric and kinetic study for evaluating the thermal stability of edible oils by $1 \mathrm{H}$ NMR analysis: Comparison of methods. Talanta Elsevier; 88:358-368 (2012).

37 R Core team. R Core Team. R A Lang. Environ. Stat. Comput. R Found. Stat. Comput. , Vienna, Austria. ISBN 3-900051-07-0, URL http//www.R-project.org/. p. 275-286 2015.

38 Li A, Yuan B, Li W, Wang F, and Ha Y. Thermally induced isomerization of linoleic acid in soybean oil. Chem Phys Lipids 166:55-60 (2013).

39 Frankel EN. Lipid Oxidation. Dundee, Scotland: The Oily Press; 1998.

40 Tsuzuki W. Effects of antioxidants on heat-induced trans fatty acid formation in triolein and trilinolein. Food Chem 129:104-109 (2011).

41 Sathe SK, Seeram NP, Kshirsagar HH, Heber D, and Lapsley KA. Fatty Acid Composition of California Grown Almonds. J Food Sci 73:C607-C614 (2008).

42 Beltrán Sanahuja A and Garrigós Selva MC. Study of the oxidative stability of almonds based on different parameters and techniques: Application to cultivar authenticity. Cultivars: Chemical Properties, Antioxidant Activities and Health Benefits Analytical Chemistry, Nutrition and Food Sciences Department, University of Alicante, Alicante, Spain: Nova Science Publishers, Inc.; p. 1972242013.

43 Kodad O, Estopañán G, Juan T, Alonso JMM, Espiau MTT, and Socias i Company R. Oil content, fatty acid composition and tocopherol concentration in 
the Spanish almond genebank collection. Sci Hortic (Amsterdam) 177:99-107 (2014).

44 Bolling BW, Dolnikowski G, Blumberg JB, and Chen CYO. Polyphenol content and antioxidant activity of California almonds depend on cultivar and harvest year. Food Chem 122:819-825 (2010).

45 López-Ortiz CMCM, Prats-Moya S, Beltrán Sanahuja A, Maestre-Pérez SESE, Grané-Teruel N, and Martín-Carratalá MLML. Comparative study of tocopherol homologue content in four almond oil cultivars during two consecutive years. $J$ Food Compos Anal 21:144-151 (2008).

46 Ramasubramanian K and Singh A. Machine Learning Using R - A Comprehensive Guide to Machine Learning. Springer eBooks. 2017. 


\section{Figure Captions}

Figure 1. FTIR-difference spectra corresponding to MR oil cultivar at different days of the heating treatment (left); FTIR-difference spectra in the region $1070-850 \mathrm{~cm}^{-1}$ for MR cultivar oil at different days of the thermal treatment (bands associated to trans and CLA $\mathrm{CH}$ bending vibrations). The bands at 988,970 and $947 \mathrm{~cm}^{-1}$ are associated with transtrans CLA, trans fatty acids, and trans-cis or cis-trans CLA, respectively

Figure 2. Summary of the kinetic parameters of the FTIR bands of different almond oils,

a) kinetic coefficients $\left(k, d^{-1}\right)$, b) induction time ( $t_{\text {ind }}$, days). Error bars show the maximum and minimum values obtained in each case.

Figure 3. Correlogram of the kinetic parameters of different almond oils. Size of circles is related to the Pearson coefficient. Crosses highlight non-significant correlations $(\mathrm{P}<0.05)$. Red means negative, and blue positive, correlation.

Figure 4. Variable loadings plot of the kinetic parameters on PC1 and PC2 (a) Sample loadings plot on PC1 and PC2 (b).

Figure 5. Stacked Histogram of Discriminant Function values for the training set of samples. 
Figure 1. FTIR-difference spectra corresponding to MR oil cultivar at different days of the heating treatment (left); FTIR-difference spectra in the region $1070-850 \mathrm{~cm}^{-1}$ for MR cultivar oil at different days of the thermal treatment (bands associated to trans and CLA CH bending Pros

vil rations). The bands at 988, 970 and $947 \mathrm{~cm}^{-1}$ are associated with trans-trans CLA, trans fatty acids, and trans-cis or cis-trans CLA,

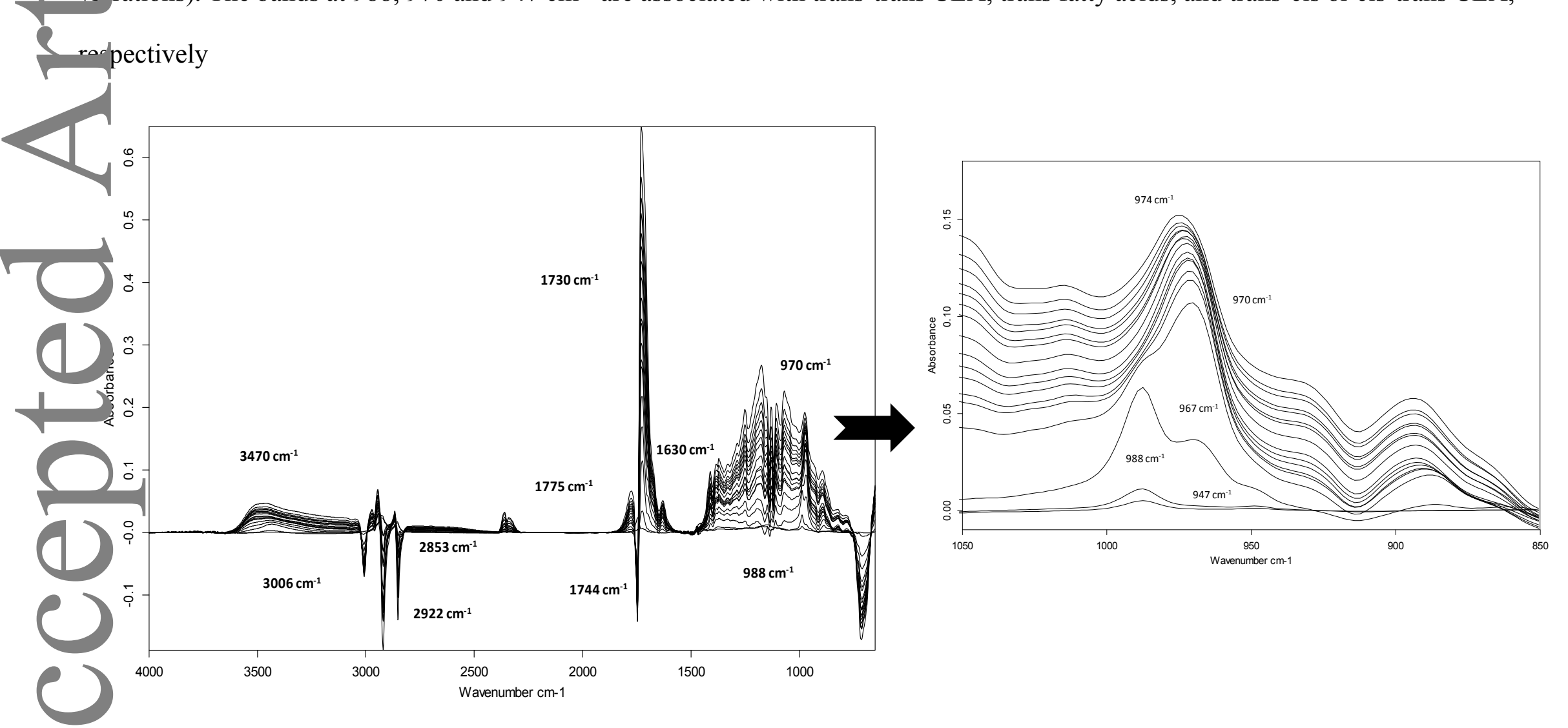


$0.3-$

$0.2-$

(1)

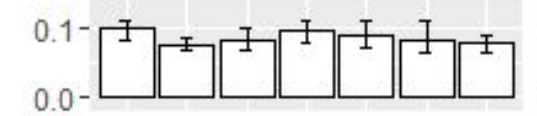

1730

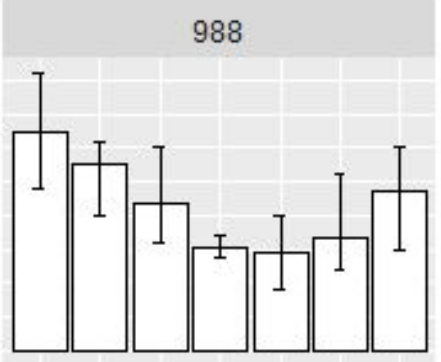

3006

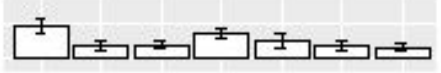

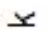
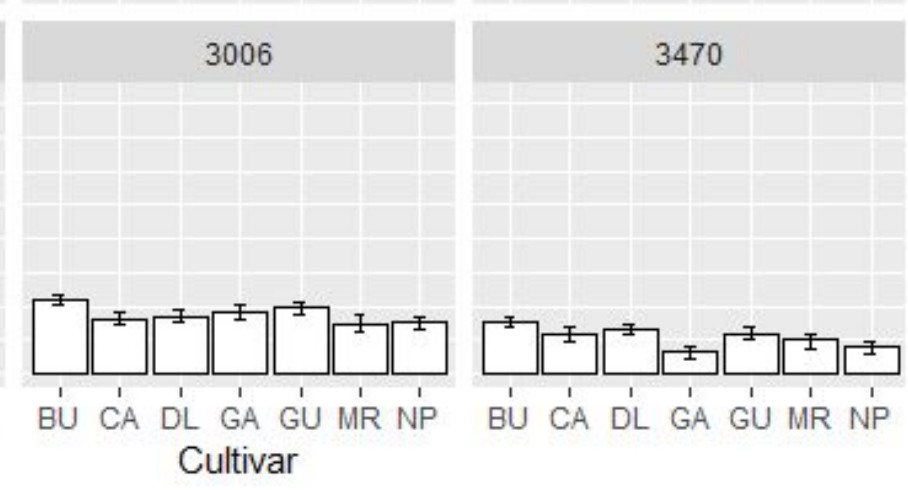

BU CA DL GA GU MR NP

\section{0}

988

1630
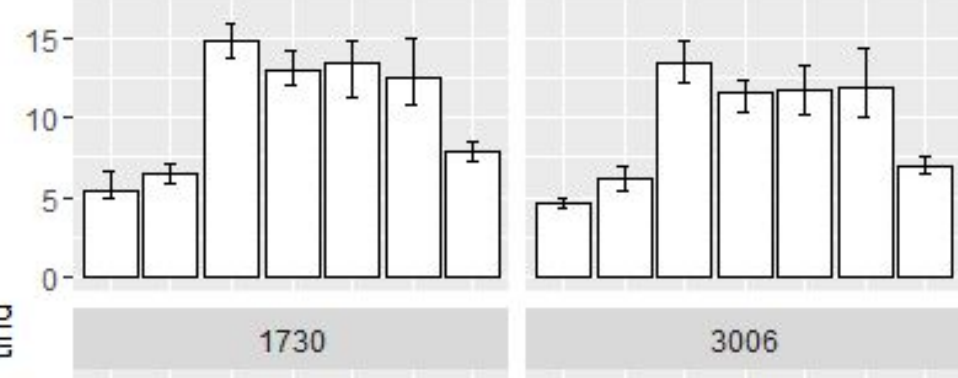

3006
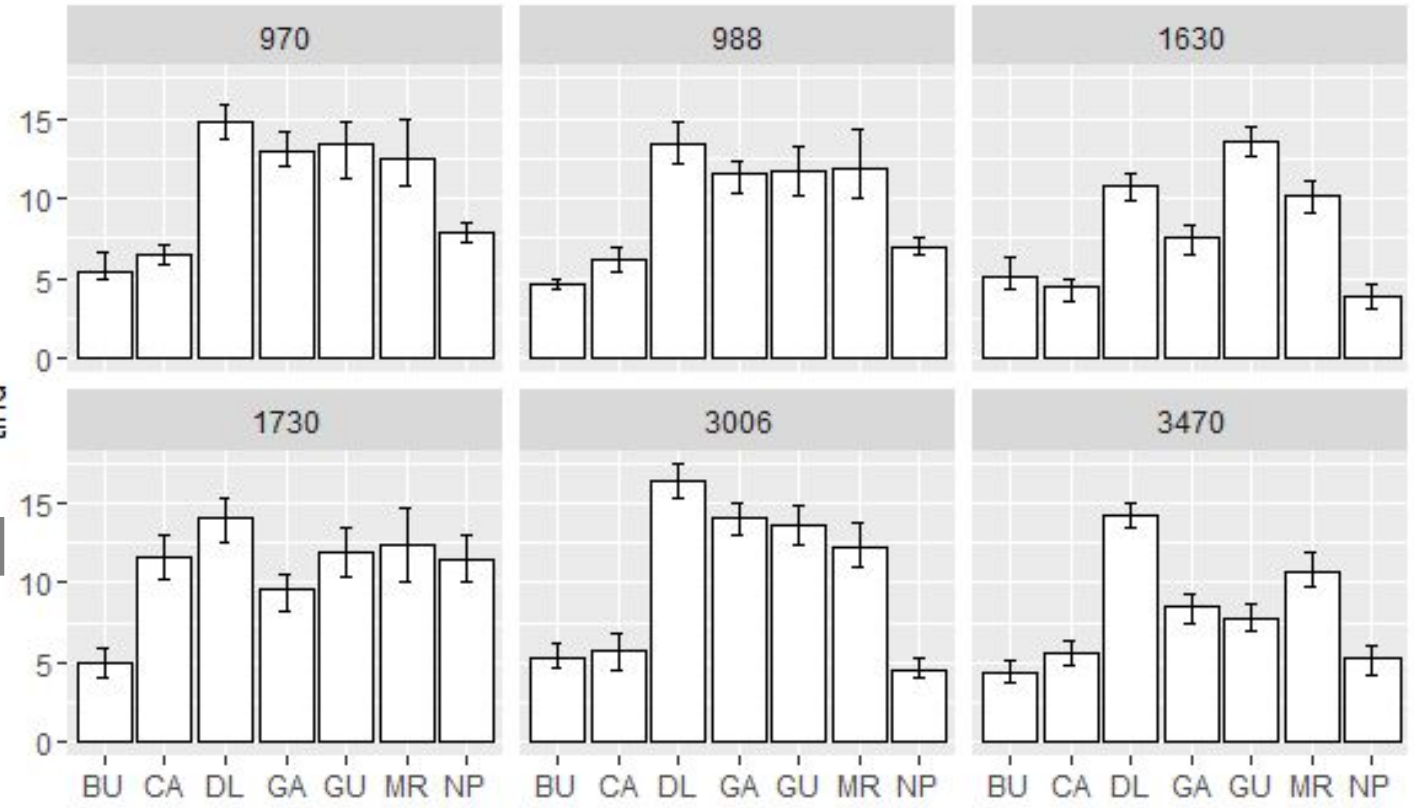

(2)
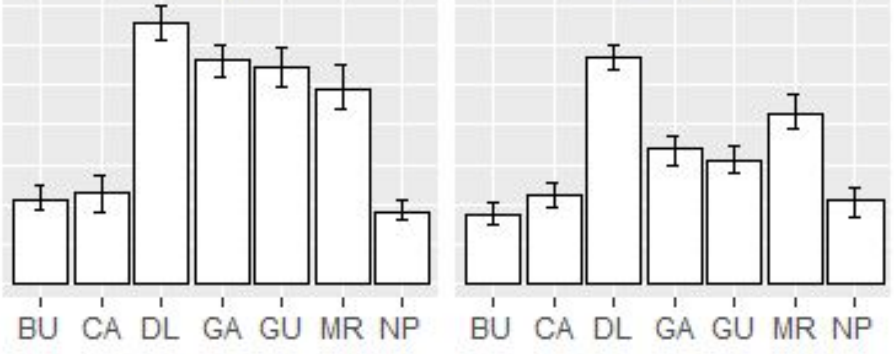

Cultivar

Figure 2. Kinetic parameters obtained for the signal of the FTIR bands corresponding to the seven almond oils, a) kinetic coefficients $\left(k\right.$, day $\left.\left.^{-1}\right), b\right)$ induction times $\left(t_{\text {ind }}\right.$, days). Error bars show the maximum and minimum values obtained in each case. 


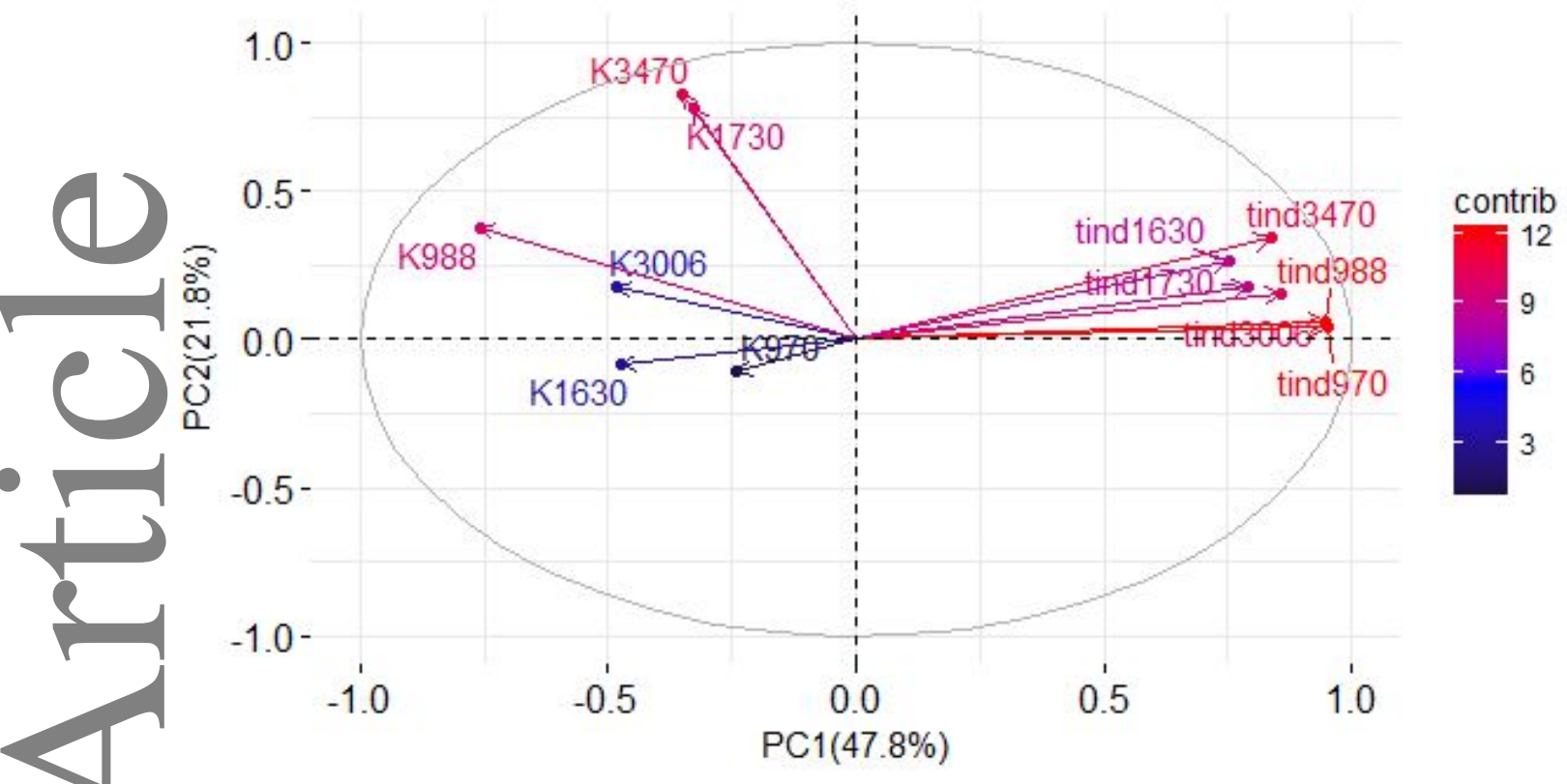

b)

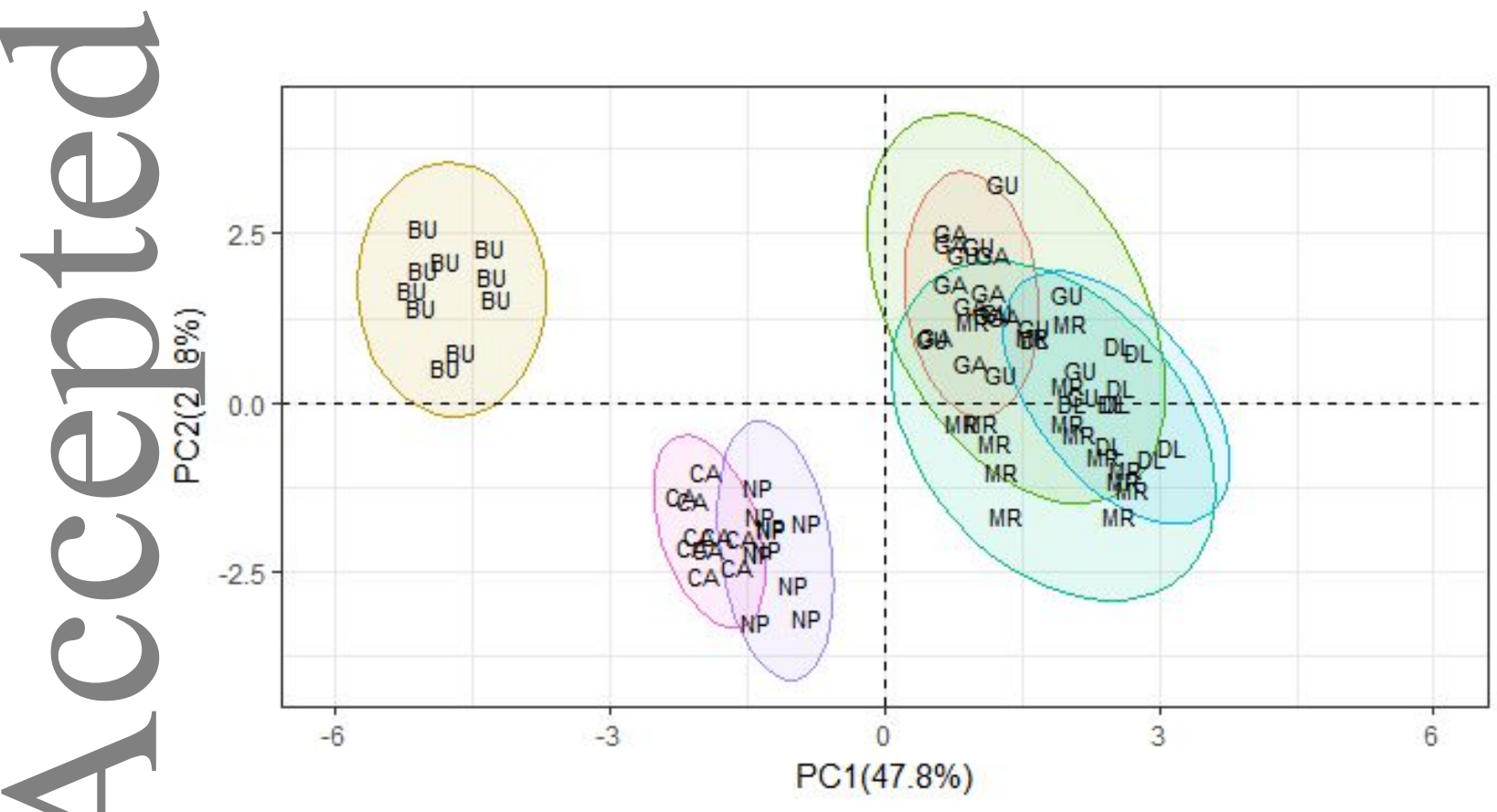

Figure 4. Variable loadings plot of the kinetic parameters on PC1 and PC2(a), and sample loading plot on PC1 and PC2 (b). 


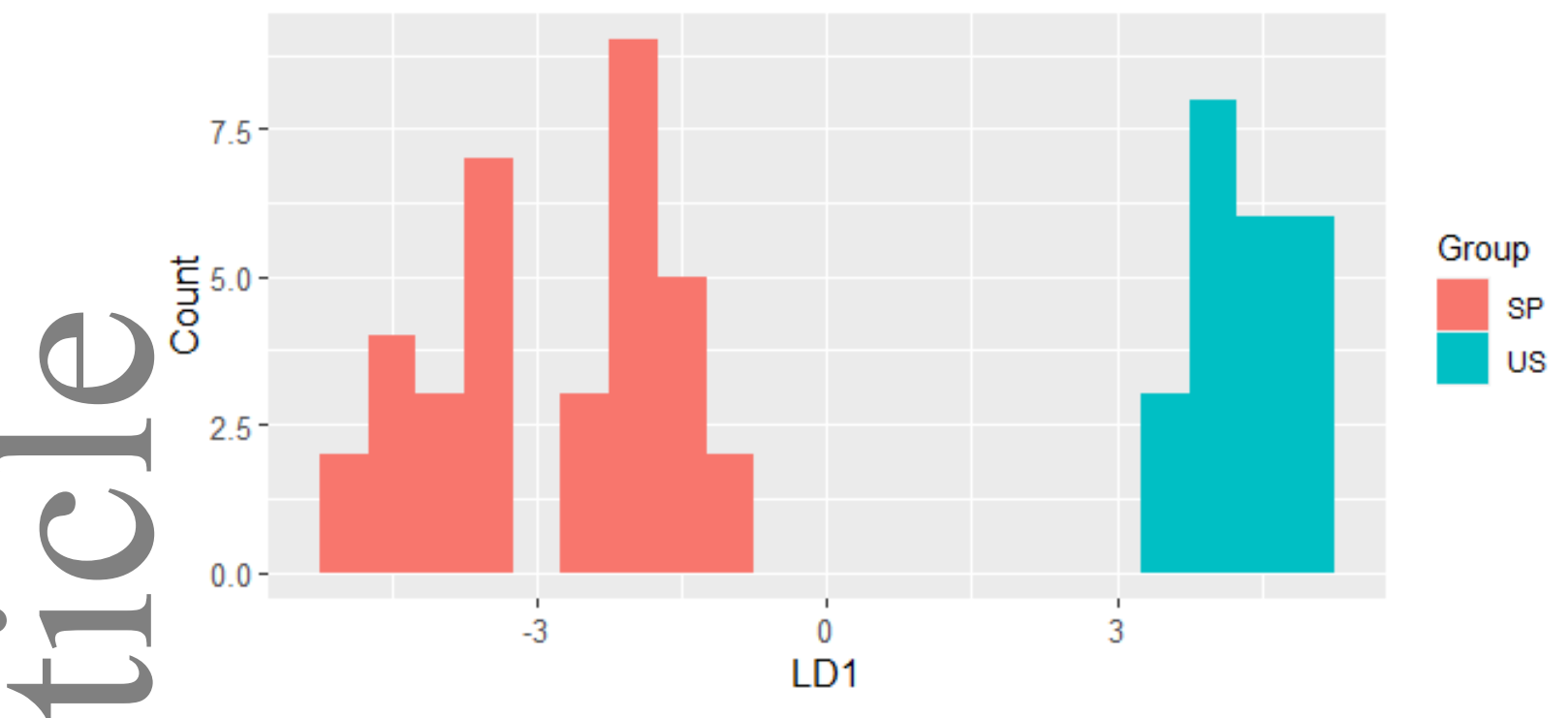

Figure 5. Stacked Histogram of Discriminant Function values for the training set of samples.

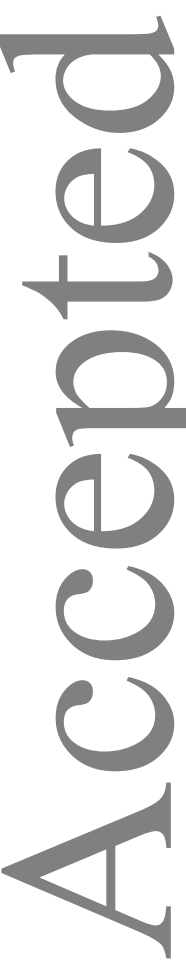


Table 1. Summary of kinetics equations for different reaction rate orders.

\section{Zero order}

$$
r=-\frac{1}{a} \frac{d[A]}{d t}=[A]^{0}
$$

$[A]=[A]_{0}-k\left(t-t_{0}\right)$

$[A]$ vs $t$

$S_{A}=S_{A 0}-k / k_{A}\left(t-t_{0}\right)$

$\ln S_{A}=\ln S_{A_{0}}-k\left(t-t_{0}\right)$

D tegrated rate equation

(dignal function)

integrated rate law for

'oducts

$$
[P]=k\left(t-t_{0}\right)
$$$$
[P]=[P]_{\infty}\left(1-e^{-k\left(t-t_{0}\right)}\right)
$$

First order

$r=-\frac{1}{a} \frac{d[A]}{d t}=k[A]$

$[A]=[A]_{0} e^{-k\left(t-t_{0}\right)}$

$$
\ln [A] \text { vs } t
$$

inear equation

$$
[P]=k /\left(t-t_{0}\right)
$$

$$
\ln \frac{[P]_{\infty}-[P]}{[P]_{\infty}}=k\left(t-t_{0}\right)
$$

$$
[P] \text { vs } t
$$

$$
\ln \frac{[P]_{\infty}-[P]}{[P]_{\infty}} \text { vs } t
$$

$$
S_{P}=\frac{k}{k_{P}}\left(t-t_{0}\right)
$$

$$
\ln \frac{S_{P_{\infty}}-S_{P}}{S_{P_{\infty}}}=k\left(t-t_{0}\right)
$$

(cignal function)

$\vec{k}=$ ate coefficient

$k_{A} k_{P}$ proportionality coefficient that relates concentration of reactant or product to signal. 
Table 2. Summary of the kinetic parameters obtained from the variation with time of the absorbance of the selected spectral features. Cultivar: MR.

\begin{tabular}{|c|c|c|c|c|c|c|}
\hline Band & $\begin{array}{l}\text { range } \\
\text { (day) }\end{array}$ & $\begin{array}{l}\mathrm{k} \pm \mathrm{t}_{(\mathrm{n}-2)} \mathrm{s}_{\mathrm{k}} \\
\left(\mathrm{day}^{-1}\right)\end{array}$ & $\ln \mathrm{S}(\mathrm{R})_{0} \pm \mathrm{t}_{(\mathrm{n}-2)} \mathrm{S}\left(\ln \mathrm{S}(\mathrm{R})_{0}\right)$ & $\mathrm{r}$ & $\mathrm{n}$ & $\begin{array}{l}\mathrm{t}_{\text {ind }} \pm \mathrm{S}_{\mathrm{t} \text { ind }} \\
\text { (day) }\end{array}$ \\
\hline 70 & {$[2-22]$} & $0.049 \pm 0.006$ & $0.055 \pm 0.09$ & -0.997 & 9 & $1.1 \pm 0.7$ \\
\hline 06 & [4-25] & $0.126 \pm 0.005$ & $-2.34 \pm 0.07$ & -0.999 & 11 & $3.3 \pm 0.3$ \\
\hline 7,30 & {$[2-27]$} & $0.043 \pm 0.002$ & $0.077 \pm 0.03$ & -0.997 & 13 & $1.8 \pm 0.4$ \\
\hline 30 & {$[6-34]$} & $0.073 \pm 0.003$ & $0.38 \pm 0.06$ & -0.999 & 11 & $5.1 \pm 0.3$ \\
\hline 8 & {$[2-6]$} & $0.51^{\mathrm{a}}$ & $1.3^{\mathrm{a}}$ & -0.964 & 3 & $2.4 \pm 1.4$ \\
\hline 0 & [8-18] & $0.137 \pm 0.004$ & $0.45 \pm 0.07$ & -0.999 & 7 & $3.3 \pm 0.2$ \\
\hline
\end{tabular}

a. The errors associated with these parameters are not provided because the regression was performed with data from just three measurements. 
